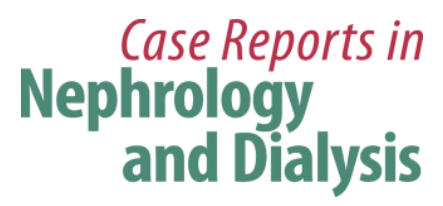

Case Rep Nephrol Dial 2017;7:130-137

DOI: $10.1159 / 000480009$

Published onlıne: September 27, 2017

\title{
Novel de novo AVPR2 Variant in a Patient with Congenital Nephrogenic Diabetes Insipidus
}

\author{
Shivani Joshi ${ }^{a} \quad$ Per Brandstrom $^{b} \quad$ Niels Gregersen ${ }^{c} \quad$ Søren Rittig ${ }^{a, d}$ \\ Jane Hvarregaard Christensen ${ }^{\mathrm{e}}$ \\ ${ }^{a}$ Department of Clinical Medicine, Child and Youth Research Laboratory, Aarhus \\ University, Aarhus, Denmark; ${ }^{b}$ Queen Silvia Children's Hospital, Department of Pediatrics, \\ Institute of Clinical Sciences, Sahlgrenska Academy, Gothenburg University, \\ Gothenburg, Sweden; 'Department of Clinical Medicine, Research Unit for Molecular \\ Medicine, Aarhus University, Aarhus, Denmark; ${ }^{d}$ Department of Pediatrics, Aarhus \\ University Hospital, Aarhus, Denmark; ${ }^{\mathrm{e}}$ Department of Biomedicine, Aarhus University, \\ Aarhus, Denmark
}

\section{Keywords}

AVPR2 - Congenital nephrogenic diabetes insipidus - De novo disease-causing variant . Vasopressin V2 receptor - Diagnostic testing

\begin{abstract}
Early diagnosis and treatment of congenital nephrogenic diabetes insipidus (CNDI) are essential due to the risk of intellectual disability caused by repeated episodes of dehydration and rapid rehydration. Timely genetic testing for disease-causing variants in the arginine vasopressin receptor 2 (AVPR2) gene is possible in at-risk newborns with a known family history of X-linked CNDI. In this study, a Swedish male with no family history was diagnosed with CNDI at 6 months of age during an episode of gastroenteritis. We analyzed the coding regions of $A V P R 2$ by PCR and direct DNA sequencing and identified an 80-bp duplication in exon 2 (GenBank NM_000054.4; c.800_879dup) in the proband. This variant leads to a frameshift and introduces a stop codon four codons downstream (p.Ala294Profs*4). The variant gene product either succumbs to nonsense-mediated decay or is translated to a truncated nonfunctional vasopressin V2 receptor. This variant was absent in four unaffected fami-
\end{abstract}




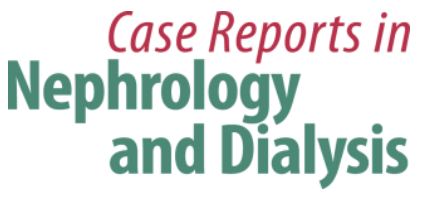

Case Rep Nephrol Dial 2017;7:130-137

DOI: $10.1159 / 000480009$

C 2017 The Author(s). Published by S. Karger AG, Basel www.karger.com/cnd

Joshi et al.: Novel de novo AVPR2 Variant in a Patient with Congenital Nephrogenic Diabetes Insipidus

ly members, including his parents, as well as in 100 alleles from healthy controls, and is thus considered a novel de novo disease-causing variant. Identification of the disease-causing variant facilitated precise diagnosis of CNDI in the proband. Furthermore, it allows future genetic counseling in the family. This case study highlights the importance of genetic testing in sporadic infant cases with CNDI that can occur due to de novo variants in AVPR2 or several generations of female transmission of the disease-causing variant.

(C) 2017 The Author(s)

Published by S. Karger AG, Basel

\section{Introduction}

Congenital nephrogenic diabetes insipidus (CNDI) is a rare disease characterized by the inability of the renal collecting tubules to respond to normal or high levels of arginine vasopressin (AVP), also known as the antidiuretic hormone. Inherited forms of CNDI can, in conjunction with evaluation of their inheritance patterns (either X-linked or autosomal), be differentiated by molecular genetic analysis of the arginine vasopressin receptor 2 (AVPR2) and the aquaporin 2 (AQP2) genes. Almost $90 \%$ of patients with CNDI are boys with a diseasecausing variant in AVPR2 located on Xq28 (X-linked CNDI, OMIM \#304800). More than 250 disease-causing variants have been identified in AVPR2 causing X-linked CNDI [1]. AVPR2 spans three coding exons and encodes the vasopressin V2 receptor (V2R). V2R is primarily expressed in the principal cells of the renal collecting ducts. Binding of AVP to V2R stimulates reabsorption of water and prevents dehydration. Hence, patients with defects in AVPR2 present with polyuria, polydipsia, severe dehydration, severe hypernatremia, poor weight gain, poor feeding, failure to thrive, vomiting, fever, constipation, and occasionally seizures [2]. This defect in urine concentration usually presents shortly after birth or during the first weeks of life. Early diagnosis and treatment are essential as patients are at risk of developing intellectual disability due to repeated episodes of dehydration and edema in the brain (after rapid rehydration). Newborns with a known family history of X-linked CNDI are often diagnosed and treated early, based on genetic testing for disease-causing variants in AVPR2. However, de novo variants can cause a delay in diagnosis, and even inherited variants (apart from de novo variants) can also be masked by several generations of female transmission and thus be associated with delayed diagnosis. In this study, we describe the clinical course and identification of novel de novo 80-bp duplication in AVPR2 in a Swedish patient with CNDI.

\section{Case Report}

The proband, a Swedish male, had no family history of diabetes insipidus. He was clinically diagnosed with CNDI at the pediatric department of a county hospital in Sweden during an episode of gastroenteritis with vomiting, watery diarrhea, and stagnant growth at 6 months of age. At presentation, he was severely dehydrated with highly elevated serum sodium $(175 \mathrm{mmol} / \mathrm{L})$, serum chloride $(124 \mathrm{mmol} / \mathrm{L})$, and serum osmolality $(350 \mathrm{mOsm} / \mathrm{kg})$. He had massive polyuria $(15 \mathrm{~mL} / \mathrm{kg} / \mathrm{h})$ and concurrent low urine osmolality of 140 $\mathrm{mOsm} / \mathrm{kg}$ despite increased levels of plasma AVP $(17 \mathrm{ng} / \mathrm{L}$, reference $<8 \mathrm{ng} / \mathrm{L})$. There was no significant change in urine osmolality or diuresis after desmopressin had been administered subcutaneously up to $4 \mu \mathrm{g} / \mathrm{dose}$. Despite high serum osmolality from fluid deprivation due to the gastroenteritis and urine loss, the urine of the proband was severely diluted. He 


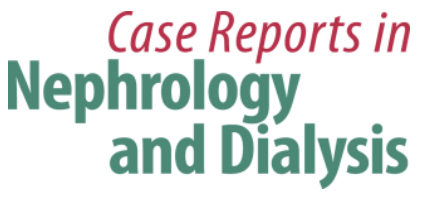

Case Rep Nephrol Dial 2017;7:130-137 DOI: 10.1159/000480009

C 2017 The Author(s). Published by S. Karger AG, Basel www.karger.com/cnd

Joshi et al.: Novel de novo AVPR2 Variant in a Patient with Congenital Nephrogenic Diabetes Insipidus

was diagnosed with CNDI based on the findings mentioned above, including his lack of response to desmopressin, however without a formal fluid deprivation test since further fluid restriction was considered not only redundant but also inappropriate in this very sick 6month-old baby.

When the CNDI diagnosis was established, the family acknowledged that his diapers had been heavier already from birth, as compared to those of his two older brothers. Oral treatment with hydrochlorothiazide and amiloride was commenced at the age of 7 months. Due to feeding problems, he was switched from breastfeeding to bottle. Stagnant weight and height growth was observed from median values at birth to -3.5 standard deviations (SD) at 6 months of age. As there was no catch-up in either weight or height at 6 years of age, he was assessed for growth hormone (GH) deficiency and was found to have subnormal peak levels of GH during an overnight GH profile $(19.5 \mu \mathrm{g} / \mathrm{L}$, reference $>20 \mu \mathrm{g} / \mathrm{L})$ and subnormal levels of IGF1 (-1.6 SD) and IGF1-BP3 (-0.8 SD).

\section{Clinical Course and Outcome}

The urine volumes passed by the proband decreased gradually after administration of oral amiloride $(0.3 \mathrm{mg} / \mathrm{kg} /$ day $)$ and hydrochlorothiazide $(3 \mathrm{mg} / \mathrm{kg} /$ day). Indomethacin was tried for a short period, but was discontinued after 3 weeks due to a skin rash. After several years of treatment he developed severe hypokalemia. Thus, hydrochlorothiazide was reduced and eventually discontinued. The proband was also kept on a low-sodium diet (no extra salt added to food). On renal ultrasound at 3 and 6 years of age, the renal parenchyma was normal, with slight bilateral dilatation of the renal pelvises. Regular GH substitution was commenced at the age of 8 years, with a mean daily dose of $1 \mathrm{mg} / \mathrm{m}^{2} /$ day, resulting in height and weight catch-up from -3.5 to $-0.5 \mathrm{SD}$. GH substitution was discontinued at 17 years of age.

As a teenager, the patient discontinued all oral medicines, preferring passing large amounts of urine (up to $8 \mathrm{~L} /$ day) to the use of medication. At last follow-up at the age of 19 years, serum sodium was $140 \mathrm{mmol} / \mathrm{L}$, serum chloride $104 \mathrm{mmol} / \mathrm{L}$, and the urine output had decreased from approximately 8 to $5 \mathrm{~L}$ daily. The cognitive development and school performance of the proband were not formally tested but considered normal throughout childhood and until the last follow-up at 19 years of age.

\section{Genetic Analysis}

The proband was 7.5 years old when he was referred for genetic analysis. Blood samples for genetic testing were collected from all family members after obtaining informed consent from the parents of the patient and his two unaffected older brothers (Fig. 1). Genomic DNA was extracted from leukocytes using standard procedures. The three coding exons of AVPR2 were amplified by PCR as described previously [3]. PCR fragments were sequenced by bidirectional direct sequencing using the Big Dye Terminator v1.1 Cycle Sequencing kit and the ABI3100 analyzer (Applied Biosystems, Foster City, CA, USA). Sequence data were analyzed using the Sequencer v.3.1.1 software (Gene Codes Corporation, Ann Arbor, MI, USA), with the AVPR2 cDNA sequence (GenBank NM_000054.4) as a reference.

Analysis of PCR products and sequence data obtained from the proband revealed hemizygosity for a duplication that occurs after nucleotide c.879 in exon 2 and consists of $80 \mathrm{bp}$ that are identical to the nucleotide sequence from c.800_879 (c.800_879dup) (Fig. 2 and online suppl. material; for all online suppl. material, see www.karger.com/doi/10.1159/000480009). This tandem duplication predicts a frameshift where proline replaces arginine at position p.294 in V2R, and a premature termination co- 


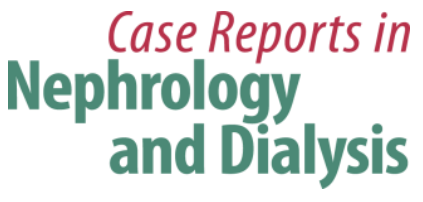

Case Rep Nephrol Dial 2017;7:130-137

DOI: $10.1159 / 000480009$

C 2017 The Author(s). Published by S. Karger AG, Basel www.karger.com/cnd

Joshi et al.: Novel de novo AVPR2 Variant in a Patient with Congenital Nephrogenic Diabetes Insipidus

don (PTC) appears four codons downstream (p.AlaAlaTrpAsp294-297>ProArgLeuStop, p.Ala294Profs*4). The c.800_879dup variant was not found in any other member of the family (Fig. 2 and online suppl. material). The variant was also absent among 100 alleles from healthy Danish individuals (from the biobank at the Department of Biomedicine, Aarhus University). These healthy subjects provided written informed consent for participation, and approval was obtained from the ethics committee for Central Denmark Region. Hence, c.800_879dup seems to be a de novo disease-causing variant. There were no other variants in the coding regions of $A V P R 2$, neither in the proband nor in any of the other family members.

\section{Discussion}

We identified a de novo 80-bp duplication in exon 2 of $A V P R 2$, which most likely caused X-linked CNDI in our proband in either of the following ways: (1) The 80-bp duplication results in a frameshift predicted to introduce a PTC four codons downstream in the shifted reading frame. PTCs are triggers for nonsense-mediated decay (NMD), a surveillance mechanism in humans to degrade faulty messenger RNA (mRNA). NMD especially targets mRNAs with truncated open reading frames due to PTCs located more than 50-55 nucleotides upstream of the $3^{\prime}$ exon-exon junction of the mRNAs [4]. There may be exceptions to this rule [5], but such exceptions have not been reported in AVPR2. In our case, the PTC is introduced approximately 102 nucleotides upstream to the $3^{\prime}$ exon-exon junction (Fig. 2). We speculate that the truncated mRNA is destroyed by NMD, resulting in no production of $\mathrm{V} 2 \mathrm{R}$, thus explaining CNDI in the proband. (2) If the prematurely terminated mRNA manages to escape NMD and undergo translation, it will produce a truncated V2R. V2R is, normally, 371 amino acids long with 7 transmembrane, 4 extracellular, and 4 cytoplasmic domains. If translated, the 80-bp duplication causes a shift in the reading frame and produces a truncated V2R that is short of 73 carboxyl-terminal residues that contain two palmitoylation sites at cysteine 341 and 342 (Fig. 2). Palmitoylation contributes to the localization of proteins in the plasma membrane. Mutation of these cysteines to serines (CysCys341/342SerSer) abolishes them as palmitoylation sites and therefore reduces the number of detectable cell surface V2R [6]. This effect is even more pronounced for truncated receptors. Sadeghi et al. [7] showed that V2R truncated at position 337 (p.Arg337*) is nonfunctional since it remains as a precursor and does not reach the plasma membrane. In any case, if the AVPR2 mRNA is not degraded by NMD, the resulting V2R is likely nonfunctional, thus causing X-linked CNDI.

To our knowledge, the 80-bp duplication identified in the present study has not been described before. The only gross duplication in AVPR2 described so far is a 28-bp duplication in a male with a neonatal onset of CNDI and with relatives carrying the same variant $[8,9]$.

Detection of variants in AVPR2 in cases with CNDI permits precise diagnosis and provides insight into the structure-function relationship of V2R. As AVPR2 comprises only three coding exons, the molecular genetic analysis is easily possible in most cases by direct DNA sequencing. It should be performed as routine diagnostics for CNDI, especially in cases like our proband. There are several benefits of genetic testing, especially in X-linked CNDI. Early detection of patients with X-linked CNDI allows for the abundant intake of water and medical treatments, including hydrochlorothiazide, amiloride, indomethacin, and low-sodium diet, thus averting physical and intellectual disability. Genetic testing of AVPR2 also empowers differential diagnosis of CNDI and identification of the (not-so-uncommon) de novo disease-causing variants [10]. In families with X-linked CNDI, not only relatives at risk should 


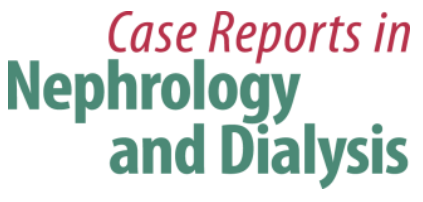

Case Rep Nephrol Dial 2017;7:130-137 DOI: 10.1159/000480009

(c) 2017 The Author(s). Published by S. Karger AG, Basel www.karger.com/cnd

Joshi et al.: Novel de novo AVPR2 Variant in a Patient with Congenital Nephrogenic Diabetes Insipidus

undergo genetic testing, but also females at risk for passing on the gene defect to their sons [11]. This information will help in genetic counseling, enable presymptomatic genetic diagnosis, and reduce morbidity by ensuring prompt treatment of newborns with the gene defect [1]. In the case of AVPR2 gene defects, prenatal genetic testing can be done in high-risk pregnancies after karyotyping of fetal cells that reveal a 46,XY karyotype. Moreover, preimplantation genetic testing would also be an option for families with already identified diseasecausing variants.

Unidentified CNDI can be life-threatening in infancy due to severe dehydration and hypernatremia in circumstances with inadequate fluid intake or increased fluid losses. Repeated episodes of hypernatremia are also believed to cause permanent brain damage responsible for the poor intellectual development that has been associated with CNDI. As seen in the proband of this study, early recognition of the disease is of great importance to avoid these detrimental consequences [1]. The long-term treatment of CNDI aims at keeping serum sodium at the lower normal range by low-sodium diet and hydrochlorothiazide-induced excretion of sodium in the distal tubules by blocking the $\mathrm{Na}-\mathrm{Cl}$ cotransporter. This will lead to sodium and water retention in the proximal tubule, reducing the amount of water entering the ascending loop of Henle and the distal convoluted tubule [12]. The stunted growth seen in many patients with CNDI is believed to be secondary to the large amounts of water these children need to drink, at the expense of nutritional feeds. However, in this particular case, we detected marginally reduced peak levels of nocturnal GH together with subnormal levels of IGF1 and IGF1-BP3. Based on this and a height percentile of -3.5 SD, GH therapy was introduced. After 9 years of GH substitution, the patient's height was corrected to -0.5 SD. Lejarraga et al. [13] observed a height correction of 1.06 SD (from -2.36 to -1.30 SD) in 14 patients with CNDI without GH therapy over a median follow-up period of 11.6 years. Although no systematic studies have been performed, the constant tendency of dehydration in patients with CNDI has been speculated to have an unknown consequence in the secretion of GH [14]. The subtle GH deficiency in our patient, together with the height correction from -3.05 to $-0.5 \mathrm{SD}$ under GH therapy, is indicative of such an association and should be investigated further.

In conclusion, we describe a novel de novo 80-bp duplication, c.800_879dup, in AVPR2 that causes a frameshift p.Ala294Profs*4, which either succumbs to NMD of the AVPR2 mRNA or nonfunctional V2 receptor, thus explaining X-linked CNDI in our proband. Our proband was clinically diagnosed at the age of 6 months and genetically diagnosed at 7.5 years of age. Identification of the genetic cause of CNDI in the proband confirmed the CNDI diagnosis and allowed future genetic counseling.

\section{Acknowledgment}

We sincerely thank the patient and family members for their enthusiastic participation. We also thank Jane Knudsen and Margrethe Kjeldsen for their skillful technical assistance.

\section{Statement of Ethics}

Blood samples for genetic testing were collected from all family members after obtaining informed consent from the parents of the patient and his two unaffected older brothers. 


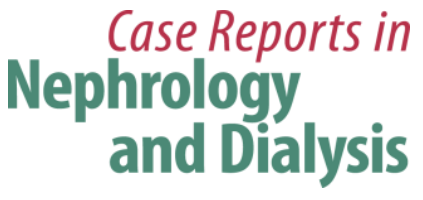

Case Rep Nephrol Dial 2017;7:130-137 DOI: $10.1159 / 000480009$

C 2017 The Author(s). Published by S. Karger AG, Basel www.karger.com/cnd

Joshi et al.: Novel de novo AVPR2 Variant in a Patient with Congenital Nephrogenic Diabetes Insipidus

The healthy subjects provided written informed consent for participation. The approval was obtained from the Ethics Committee for Central Denmark Region.

\section{Disclosure Statement}

The authors declare no conflicts of interest.

\section{Author Contributions}

All authors approved the final version of the manuscript. S. Joshi: drafting of the article and critical revision for important intellectual content. S. Joshi, P. Brandstrom, S. Rittig, N. Gregersen, and J.H. Christensen: substantial contributions to conception and design, acquisition of data, data analysis and interpretation, as well as editing of the manuscript. J.H. Christensen: final approval of the version to be submitted and any revised version.

\section{References}

1 Bichet DG, Bockenhauer D: Genetic forms of nephrogenic diabetes insipidus (NDI): vasopressin receptor defect (X-linked) and aquaporin defect (autosomal recessive and dominant). Best Pract Res Clin Endocrinol Metab 2016;30:263-276.

2 Wesche D, Deen PM, Knoers NV: Congenital nephrogenic diabetes insipidus: the current state of affairs. Pediatr Nephrol 2012;27:2183-2204.

-3 Kamperis K, Siggaard C, Herlin T, Nathan E, Hertz JM, Rittig S: A novel splicing mutation in the V2 vasopressin receptor. Pediatr Nephrol 2000;15:43-49.

$\checkmark 4$ Nagy E, Maquat LE: A rule for termination-codon position within intron-containing genes: when nonsense affects RNA abundance. Trends Biochem Sci 1998;23:198-199.

5 Wang J, Gudikote JP, Olivas OR, Wilkinson MF: Boundary-independent polar nonsense-mediated decay. EMBO Rep 2002;3:274-279.

6 Sadeghi HM, Innamorati G, Dagarag M, Birnbaumer M: Palmitoylation of the V2 vasopressin receptor. Mol Pharmacol 1997;52:21-29.

7 Sadeghi HM, Innamorati G, Birnbaumer M: An X-linked NDI mutation reveals a requirement for cell surface V2R expression. Mol Endocrinol 1997;11:706-713.

8 Wildin RS, Antush MJ, Bennett RL, Schoof JM, Scott CR: Heterogeneous AVPR2 gene mutations in congenital nephrogenic diabetes insipidus. Am J Hum Genet 1994;55:266-277.

-9 Spanakis E, Milord E, Gragnoli C: AVPR2 variants and mutations in nephrogenic diabetes insipidus: review and missense mutation significance. J Cell Physiol 2008;217:605-617.

10 Faerch M, Christensen JH, Corydon TJ, Kamperis K, de Zegher F, Gregersen N, Robertson GL, Rittig S: Partial nephrogenic diabetes insipidus caused by a novel mutation in the AVPR2 gene. Clin Endocrinol (Oxf) 2008;68:395-403.

11 Faerch M, Corydon TJ, Rittig S, Christensen JH, Hertz JM, Jendle J: Skewed X-chromosome inactivation causing diagnostic misinterpretation in congenital nephrogenic diabetes insipidus. Scand J Urol Nephrol 2010;44:324-330.

12 Loffing J: Paradoxical antidiuretic effect of thiazides in diabetes insipidus: another piece in the puzzle. J Am Soc Nephrol 2004;15:2948-2950.

$\checkmark 13$ Lejarraga H, Caletti MG, Caino S, Jimenez A: Long-term growth of children with nephrogenic diabetes insipidus. Pediatr Nephrol 2008;23:2007-2012.

14 van Lieburg AF, Knoers NV, Monnens LA: Clinical presentation and follow-up of 30 patients with congenital nephrogenic diabetes insipidus. J Am Soc Nephrol 1999;10:1958-1964.

15 Faerch M, Christensen JH, Rittig S, Johansson JO, Gregersen N, de Zegher F, Corydon TJ: Diverse vasopressin V2 receptor functionality underlying partial congenital nephrogenic diabetes insipidus. Am J Physiol Renal Physiol 2009;297:F1518-F1525. 


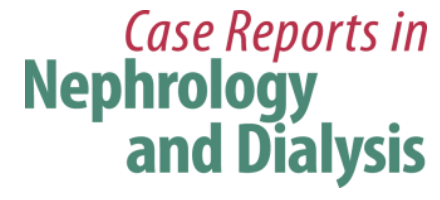

Case Rep Nephrol Dial 2017;7:130-137 DOI: $10.1159 / 000480009$

(c) 2017 The Author(s). Published by S. Karger AG, Basel

Joshi et al.: Novel de novo AVPR2 Variant in a Patient with Congenital Nephrogenic Diabetes Insipidus

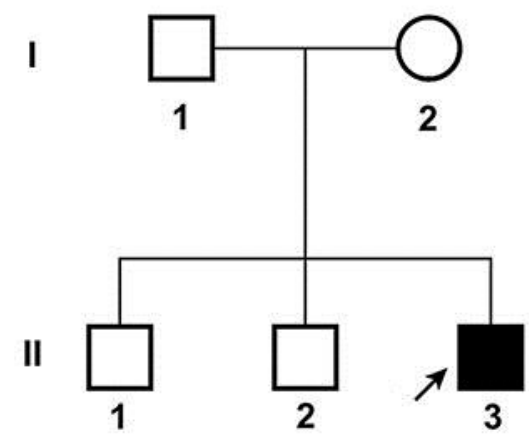

Fig. 1. Pedigree of a Swedish case with congenital nephrogenic diabetes insipidus. Squares, males; circle, female; filled symbol with an arrow, affected proband. All family members were genetically tested. 


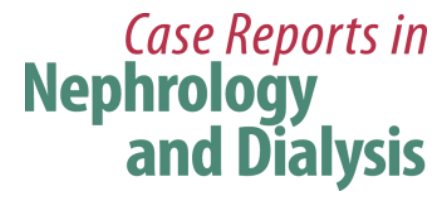

Case Rep Nephrol Dial 2017;7:130-137

DOI: $10.1159 / 000480009$

(C) 2017 The Author(s). Published by S. Karger AG, Basel www.karger.com/cnd

Joshi et al.: Novel de novo AVPR2 Variant in a Patient with Congenital Nephrogenic Diabetes Insipidus
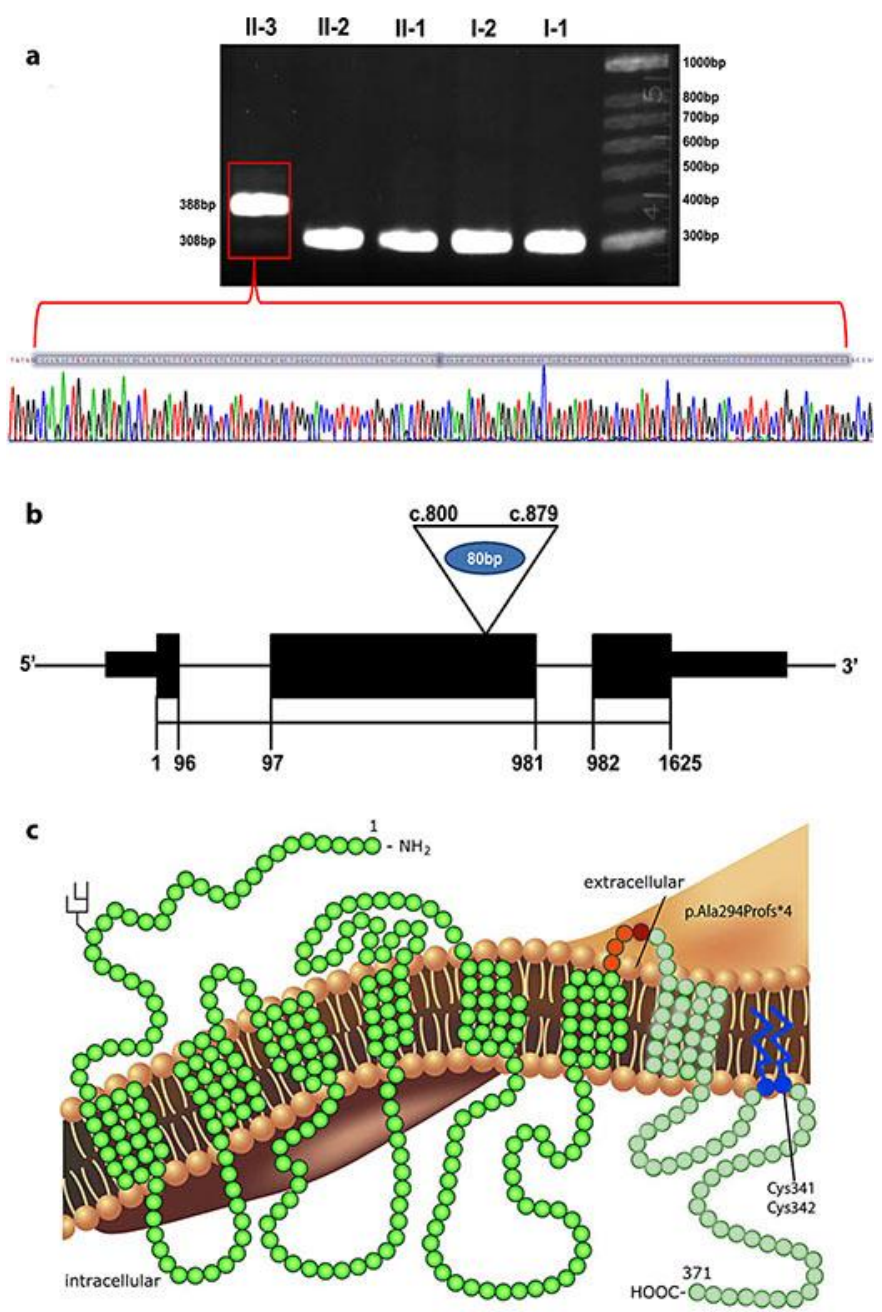

Fig. 2. Identification, illustration, and possible effect of the de novo c.800_879dup variant in AVPR2. a Agarose gel electrophoresis analysis of AVPR2 exon 2 PCR products from the patient with congenital nephrogenic diabetes insipidus and his unaffected family members. The numbers to the left of the image are the predicted sizes of the PCR products. The numbers to the right of the image are the sizes of the bands of the DNA ladder loaded in the far right lane of the gel (HyperLadderTM $50 \mathrm{bp}$, Bioline, Singapore). The PCR product from the case (II-3) migrates less than the products from the other family members (I-1, I-2, II-1, and II-2); this compares to the PCR product being approximately $80 \mathrm{bp}$ longer. The 80 -bp duplication is highlighted in the DNA sequence of the patient. $\mathbf{b}$ Location of c.800_879dup in exon 2 of AVPR2. Wide black boxes represent the three exons with cDNA numbering for respective exons, and narrow black boxes represent the untranslated regions of AVPR2. The triangle indicates the 80-bp duplication. c The duplication results in a frameshift and introduces a stop codon four codons downstream (p.Ala294Profs*4). The location of p.AlaAlaTrpAsp294-297 is indicated in orange, with orange red being Asp297 which is changed to a stop codon, followed by a black line to indicate truncated protein if mRNA is not degraded by nonsensemediated mRNA decay. The deleted 73 carboxy-terminal amino acid residues contain two possible palmitoylation sites at Cys341 and Cys342 (indicated in blue) that contribute to the localization of V2R in the plasma membrane. The amino acids are depicted in an approximate location. Illustration adapted from Faerch et al. [15]. 